\title{
TRANSFORMASI SITRONELAL DARI DESTILASI FRAKSINASI SEREH WANGI MENJADI SITRONELOL MENGGUNAKAN KATALIS Zr ${ }^{4+}$-ZEOLIT BETA
}

\author{
Retno Wulandari ${ }^{1}$, Harianingsih ${ }^{2 *}$ \\ ${ }^{1}$ Balai Teknologi Polimer - Badan Pengkajian dan Penerapan Teknologi (BPPT) \\ Kawasan Puspitek Serpong Tangerang Selatan, Banten. \\ ${ }^{2}$ Jurusan Teknik Kimia, Fakultas Teknik, Universitas Wahid Hasyim \\ Jl. Menoreh Tengah X/22 Sampangan, Semarang. \\ "Email: harianingsih@unwahas.ac.id
}

\begin{abstract}
Abstrak
Minyak sereh wangi yang banyak tumbuh di Indonesia menmpunyai kandungan antara lain sitronelal, sitronelol, geraniol, limonene, sitronelil asetat dan beberapa komponen lainnya. Sitronelal merupakan komponen paling utama. Isolasi sitronelal dapat dilakukan menggunakan destilasi fraksinasi. Pada penelitian ini dilakukan transformasi dari sitronelal hasil destilasi fraksinasi menjadi sitronelol yang digunakan di dalam industry kosmetik, sabun dan parfum. Sitronelal dapat mengalami reduksi menjadi sitronelol menggunakan hidrogenasi katalis $\mathrm{Zr}^{4+}$-zeolit beta. Dari hasil penelitian diperoleh identifikasi GC MS minyak sereh wangi hasil destilasi fraksinasi yang dianalisa mempunyai kandungan sitronelal sebesar 70,09\% pada peak 4. Sedangkan transformasi sitronelal menjadi sitronelol menggunakan hidrogenasi katalis $\mathrm{Zr}^{4+}$-zeolit beta menghasilkan sitronelol sebesar $40,93 \%$.
\end{abstract}

Kata kunci : sitronelal, sitronelol,zeolit

\section{PENDAHULUAN}

Minyak sereh wangi adalah salah satu minyak atsiri yang penting di Indonesia disamping minyak atsiri lainnya seperti minyak cengkeh, minyak nilam, dan minyak akar wangi. Minyak sereh wangi merupakan jenis minyak atsiri yang dihasilkan oleh tanaman sereh wangi (Cymbopogon). Sereh wangi memiliki dua tipe, yaitu tipe Ceylon (Srilanka) dan tipe Jawa. Tipe Ceylon hampir sebagian besar diproduksi di Pulau Srilanka, sedangkan tipe Jawa diproduksi terutama di Pulau Jawa dan Formosa, dan belakangan diproduksi juga di Amerika Tengah (Guatemala dan Honduras), dan Pulau Haiti. Komponen dalam minyak sereh wangi antara lain, sitronelal sebagai komponen utama, sitronelol, geraniol, limonene, dan turunan ester lainnya (Cellianus, 2012).

Sitronelal merupakan senyawa monoterpena yang mempunyai gugus aldehida, ikatan rangkap, dan rantai karbon. Sitronelal (3,7-dimetil-6-oktenal) merupakan monoterpena yang sebagian besar terbentuk dari metabolisme sekunder tanaman sereh. Sitronelal bersama dengan sitral, geraniol, linalool, dan sitronelol merupakan senyawa terpena yang paling penting (Nurisman,
2009). Struktur sitronelal dapat dilihat pada Gambar 1.

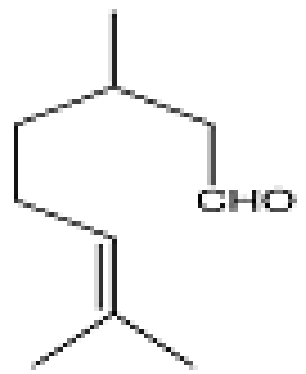

Gambar 1. Sitronelal (Celianus, 2012)

Sitronelal dihasilkan melalui proses destilasi fraksinasi minyak sereh wangi. Destilasi fraksinasi merupakan suatu proses untuk memisahkan minyak atsiri yang dalam hal ini adalah minyak sereh wangi menjadi beberapa fraksi berdasarkan perbedaan titik didih. Proses distilasi fraksinasi minyak sereh dilakukan pada tekanan di bawah tekanan atmosfer atau tekanan vakum, dan biasanya dilakukan dengan cara penyulingan minyak tanpa pengisian air dalam ketel suling atau tanpa pemasukan uap aktif ke dalam minyak. Penggunaan tekanan serendah mungkin pada proses destilasi fraksinasi minyak sereh bertujuan untuk menurunkan temperatur didih dari minyak sereh sehingga komponenkomponen yang terdapat dalam minyak sereh 
tidak terdekomposisi. Proses distilasi fraksinasi ini telah banyak diterapkan dalam industri minyak atsiri (Guenther, 1990).

Menurut Agustian (2007), sitronelal merupakan dapat ditransformasi menjadi sitronelol, isopulegol, mentol dan ester-ester lainnya yang mempunyai bau wangi yang khas. Pada penelitian ini dilakukan transformasi sitronelal menjadi sitronelol karena bau dari sitronelol sangat diminati di dalam industry parfum dan kosmetik daripada sitronelal. Penggunaan lain dari sitronelal adalah untuk pembuatan hidroksi sitronelol, dimana hidroksi sitronelal ini merupakan salah satu senyawa sintetik yang paling penting dalam wewangian. Wangi khas yang diperoleh dari sitronelol antara lain bau khas bunga lili dan mawar yang banyak orang menyebut sebagai king of parfum (rajanya wewaangian). Struktur dari sitronelol dapat dilihat pada Gambar 2.

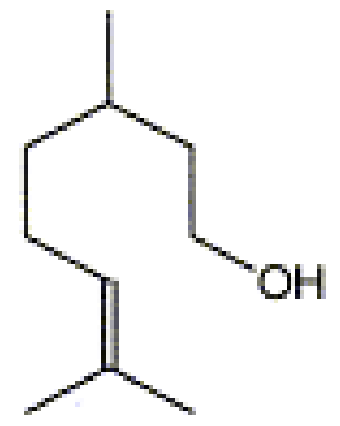

Gambar 2. Sitronelol (Celianus, 2012)

Sitronelol mempunyai nama IUPAC 3,7 dimetil 6 oktenol, dengan massa molekul $156,27 \mathrm{~g} / \mathrm{mol}$, densitas $0,855 \mathrm{~g} / \mathrm{cm}^{3}$ dan titik didih $225^{\circ} \mathrm{C}$. Sitronelol dikenal sebagai bahan yang sangat mahal dalam dunia perdagangan untuk itu dilakukan proses transformasi dari sitronelal menjadi sitronelol, dimana dalam penelitian ini digunakan hidrogenasi katalis $\mathrm{Zr}^{4+}$-Zeolit beta. Hidrogenasi katalitik dapat digunakan karena sitronelal merupakan gugus karbonil. Proses ini memerlukan panas dan tekanan. Keton akan berubah menjadi alkohol sekunder dan aldehida akan berubah menjadi alkohol primer jika mengalami proses hidrogenasi katalitik (Fessenden, 1986).

\section{METODOLOGI}

\subsection{Bahan}

Bahan-bahan yang digunakan adalah sereh wangi, aquades, etanol $\left(\mathrm{C}_{2} \mathrm{H}_{5} \mathrm{OH}\right)$ dan katalis $\mathrm{Zr}^{4+}$-Zeolit beta, $\mathrm{N}_{2}$. Alat yang digunakan antara lain magnetic stirrer, rotary evaporator vakum.
Isolasi senyawa sitronelal dari sereh dilakukan dengan cara destilasi fraksinasi. Sitronelal hasil destilasi fraksinasi diukur kadarnya menggunakan GC MS, kemudian dilakukan hidogenasi katalis menggunakan $\mathrm{Zr}^{4+}$-Zeolit beta agar terbentuk sitronelol.

\subsection{Alat}

Destilator, labu leher tiga, magnetic stirer, GC MS, alat gelas.

\subsection{Cara Kerja \\ Destilasi Fraksinasi Sitronelal}

Sitronelal diperoleh dari destilasi fraksinasi pengurangan tekanan dengan volume minyak sereh wangi sebesar $300 \mathrm{ml}$. Destilat destilat dipisahkan anatara satu dengan yang lainnya berdasarkan perbedaan titik didih kemudian fraksi sitronelal diidentifikasi menggunakan GC-MS.

\section{Reaksi hidrogenasi katalitik sitronelal menjadi sitronelol}

Proses hidrogenasi katalitik dilakukan dengan menggunakan perbandingan $\mathrm{N}_{2}: \mathrm{H}_{2}=1$ : 4. Sitronelal hasil destilasi fraksional yang telah dianalisis menggunakan GC MS dimasukkan ke dalam labu leher tiga kemudian ditambahkan katalis $\mathrm{Zr}^{4+}$-Zeolit beta, dimasukkan pula magnetic stirrer dipanaskan pada suhu $120^{\circ} \mathrm{C}$ selama 60 menit. Letakkan pada microtube dan ditambahkan $\mathrm{N}_{2}$ dan $\mathrm{H}_{2}$ selama 4 jam.Diamkan larutan selama 2 jam hingga terpisah antara padatan $\mathrm{Zr}^{4+}$-Zeolit beta dengan sitronelol, kemudian analisis sitronelol menggunakan GC MS).

\section{HASIL DAN PEMBAHASAN}

Minyak sereh wangi yang digunakan pada penelitian ini mempunyai indek bias 1,3786 dan massa jenis 0,912 g/ml. Hasil analisis GC-MS dapat dilihat pada gambar 3 . 


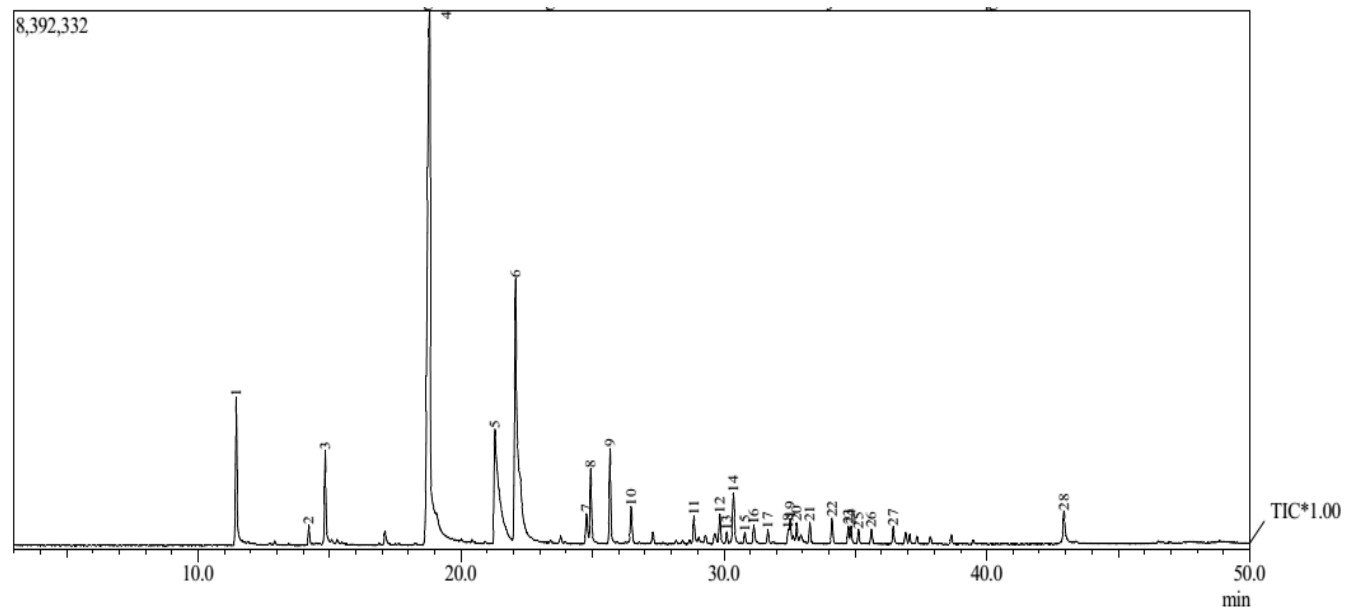

Gambar 3. Hasil GC-MS minyak sereh wangi

Pada gambar 3 menyatakan bahwa pada minyak sereh wangi yang dianalisa mempunyai kandungan sitronelal sebesar 70,09\% pada peak 4. Hal ini membuktikan bahwasanya sitronelal merupakan kandungan terbesar pada minyak sereh wangi. Pada penelitian lainnya, yang dilakukan oleh Abimanyu (2000) sitronelal yang diperoleh dari destilasi bertingkat sebesar 94,13\%. Hasil sitronelal dari destilasi fraksinasi minyak sereh dapat dilihat pada tabel 1.

Tabel 1. Data Sitronelal pada destilasi fraksinasi

\begin{tabular}{llll}
\hline $\begin{array}{l}\text { Parameter } \\
\text { Pengukuran }\end{array}$ & Fraksi 1 & Fraksi 2 & Fraksi 3 \\
\hline Titik didih $\left({ }^{\circ} \mathrm{C}\right)$ & $80-100$ & $100-120$ & $120-140$ \\
Indek bias & 1,3032 & 1,34619 & 1,3786 \\
Massa jenis $(\mathrm{g} / \mathrm{ml})$ & 0,823 & 0,871 & 0,912 \\
Kandungan & 58,74 & 64,12 & 70,09 \\
sitronelal $(\%)$ & & &
\end{tabular}

Pada tabel 1 dapat dilihat bahwa kandungan sitronelal terbesar 70,09\% ada pada fraksi 3 dengan titik didih $120-140^{\circ} \mathrm{C}$. Hal ini sesuai dengan analisa spektrofotometri yang memperlihatkan pada sitronelal fraksi 3.
Sebanyak 70,09\% sitronelal hasil destilasi fraksinasi diproses lebih lanjut menggunakan hidrogenasi katalis $\mathrm{Zr}^{4+}$-Zeolit beta. Proses hidrogenasi katalitik sitronelal menjadi sitronelol dapat dilihat pada gambar 4 .<smiles>CC(C)=CCCC(C)CC([NH3+])=O</smiles>

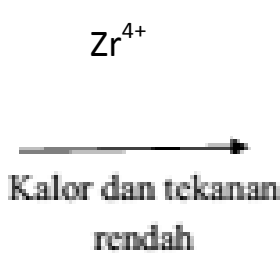

\section{Gambar 4. Reaksi hidrogenasi sitronelal menjadi sitronelol}

$\mathrm{Zr}^{4+}$ merupakan logam yang bersifat fleksibel dan dapat mempertahankan sifat pada tekanan rendah (Adzani, 2012). Sedangkan zeolite beta sebagai pengemban logam $\mathrm{Zr}$ karena bersifat stabil dan luas permukaan yang besar. Katalis $\mathrm{Zr}^{4+}$-Zeolit beta yang digunakan dalam proses hidrogenasi sebesar $15 \%$ dari berat sitronelal yang akan dihidrogenasi. Dari proses hidrogenasi sitronelal menggunakan katalis $\mathrm{Zr}^{4+}$-Zeolit beta diperoleh 40, 93\% sitronelol. Jika dibandingkan dengan penelitian 
Abimanyu (2000) dalam kajiannya mengubah sitronelal menjadi sitronelol menggunakan katalis Ni-zeolit beta diperoleh kadar sitronelol $43,91 \%$. Hasil yang diperoleh pada penelitian ini memang lebih sedikit karena pengaruh katalis. Katalis yang menggunakan Ni mempunyai aktivitas lebih tinggi daripada $\operatorname{logam} \mathrm{Zr}$.

\section{KESIMPULAN}

Berdasarkan hasil penelitian maka dapat diambil beberapa kesimpulan sebagai berikut :

1. Identifikasi GC MS sitronelal dari destilasi fraksinasi minyak sereh wangi mempunyai kadar 70,09\%.

2. Dalam reaksi hidrogenasi katalitik yang digunakan adalah katalis $\mathrm{Zr}^{4+}$-Zeolit beta karena sifatnya fleksibel.

3. Hasil hidrogenasi katalitik dari sitronelal menghasilkan sitronelol sebesar 40,93\%.

\section{DAFTAR PUSTAKA}

Abimanyu, H., M. Hanafi, \& Aiman, S., (2000), Studi Awal Pemisahan

Komponen Minyak Sereh Wangi dengan Distilasi Fraksinasi Vakum Packing Column, Prosiding Seminar Nasional Rekayasa Kimia dan Proses, Universitas Diponegoro.

Adzani,S.A.A., (2012), Karakterisasi dan Uji Aktivitas Katalis Ni/ Zeolit Hasil Preparasi pada Reaksi Hidrogenasi Perengkahan Katalitik Asam Oleat, Skripsi, Bandung: Universitas Pendidikan Indonesia.

Agustian, E., A. Sulaswatty, Tasrif, J.A. Laksmon, \& B. Adilina, (2007), Pemisahan Sitronelal dari Minyak Sereh Wangi Menggunakan Unit Fraksionasi Skala Bench, Jurnal Teknologi Industri Pertanian vol.17(2): 49-53.

Celianus, G., (2012), Kandungan Minyak Sereh Wangi.

Fessenden, (1986), Kimia Organik Jilid 2 Edisi 3. Terjemahan A.H. Pudjaatmaka. Jakarta : Penerbit Erlangga.

Guenther,E., (1990), Minyak Atsiri Jilid 4, Terjemahan Ketaren S, Jakarta: UI Press.

Nurisman, A., (2009), Sintesa Mentol dari Sitronelal dalam Proses Satu Tahap dengan Katalis Dwifungsi, Skripsi, Bogor: IPB 